ORIGINAL ARTICLE

\title{
UNUSUAL OCULAR FINDINGS IN CHILDREN'S ACUTE LEUKEMIA CASES
}

\author{
Dagmar Hejcmanová, Hana Langrová, Růžena Jebavá, Jiř́i Hak
}

Department of Ophthalmology, Charles University, Faculty of Medicine and University Teaching Hospital, Hradec Králové; (Head: prof. MUDr. P. Rozsíval, CSc.)

Department of Pardiathrics, Charles University, Faculty of Medicine and University Teaching Hospital, Hradec Králové; (Head: doc. E. Pařízková, CSc.)

Summary: The most frequent ocular findings in acute leukemia cases of children and two of our own observations are presented in this study. Emphasized are all difficulties in fixing the diagnosis and the necessity of close cooperation between ophthalmologist, pediatrist and radiologist to prevent the irreversible ocular changes.

Key words: Leukemic iris infiltration; Leukemic optic nerve head infiltration

Supported by Grant No 59/97 from Charles University Grant Agency.

Leukemia is one of the systemic diseases of all age groups that appears as an infiltration of systemic organs (10).

Allen and Straatsma (1) proved in their clinical studies the occurrence of ocular involvement in $50-70 \%$ of patients with acute leukemia, especially in tissues that are rich in vessels (uvea, retina). On the other hand, the avascular tissues (cornea, lens) have been proved not to be affected often (6). Leukemic manifestations in vitreous body are very rare (18).

Soylu et al. (17) emphasized that ophthalmologic evaluation of leukemic patients contributes in making a prognosis for the disease's advancement and may guide the theraupetic regimen choice. The team detected mainly hemorrhages of retina in 36 of 84 children suffering from acute leukemia. Neither platelet nor hematrocit values correlated with the occurrence of hemorrhages.

Ohkoshi et al. (15) noted a positive ophthalmologic finding in 28 of 63 patients with acute leukemia. In this study 27 of $29(96.4 \%)$ patients with ocular involvement died within 28 months after the diagnosis had been fixed. Bone marrow or CNS relapse has later developed in all of the disease victims (2).

All of these facts showed a high prognostic value of ocular involvement in acute leukemia.

Hatvani et al. (12) and Ells et al. (8) mention that the ocular involvement could be the first site of acute leukemia.

Ocular involvement is more common in the acute than in chronic leukemia cases. Virtually any or all of the ocular structures may be involved.

It is, however, important to distinguish primary leukemic infiltration, which is rare, from the more common secondary changes such as those due to associated anaemia, thrombocytopenia, hyperviscosity, opportunistic infections, and the side effects of cytostatic (9) or corticosteroid treatment (e.g. steroid-induced cataracts).

\section{Ocular features}

Orbit

Orbital involvement is more common in acute than in chronic leukemia cases. Orbital infiltration usually presents itself with painful proptosis, lid oedema and chemosis (Fig. 1). It occurs more frequently in the lymphoblastic than in the myeloid type of leukemia.

\section{Anterior segment}

Changes in form of nodular or diffuse infiltration of iris (Fig. 2), infiltration of the cornea (Fig. 3), spontaneous subconjunctival hemorrhages or spontaneous bleeding into the anterior chamber occur mostly in the acute myeloid leukemia patients and, very rarely, in the chronic leukemia patients.

\section{Retina}

Manifestations in retina are very frequent. In adults, we can see light tinge of retina and arteries along with venous tortuosity and dilatation of the vessels (Fig. 4), flame-shaped hemorrhages at the posterior pole of the eye, or so-called Roth's spots (i.e. yellow infiltrates surrounded by hemorrhages) may also be present (Fig. 5).

\section{Optic neuropathy (ON)}

Disc involvement is characterized by the fluffy infiltrates associated with variable disc oedema and hemorrhages (Fig. 6 ). It is important to differentiate leukemic optic neuropat- 
hy from papilloedema caused by raised intracranial pressure - secondary to meningeal infiltration. Echography of the eye according to Pierro et al (16) enables a better interpretation of the $\mathrm{ON}$ involvement. In the same way, the examination by magnetic resonance clarifies the diagnosis (19).

\section{Case reports}

\section{Isolated leukemic infiltration of the iris}

The involvement of the anterior part of uvea is rare (1) and leukemic infiltration of the iris is only sporadic $(12,20$, 11). The rise of pseudohypophyon represents the first sign of the disease's relapse, but its occurrence is rare $(5,2)$.

We are presenting the case of a 3-1/2-year-old boy. The acute lymphoblastic leukemia diagnosis was fixed at the boy's age of nine months. The child was treated according to the schedule for acute lymphocytic leukemia (ALLBFM-83), but the treatment had to be repeatedly interrupted because of bone marrow recession. The basic treatment was finished with considerable difficulties and the final aktinotherapy was done only partly due to continuous leukopenia. Neither was the treatment with L-asparaginosis brought to an end due to the allergic manifestations of the skin. The boy was in good clinical and hematological state. He was checked at the outpatient department and was treated with Merkaptopurin and Methotraxat.

The first examination by an ophthalmologist was performed on Nov.13,1991 upon the request of the boy's pediatrist who noticed anisokoria and marced iris heterochromia of the left eye.

Ocular finding:

VA OR: $5 / 5$

VA OL: certa

OR: Normal outer and intraocular finding.

OL: In the anterior chamber of completely calm eye, there was a grayish-white exudate $2 \mathrm{~mm}$ high with horizontal surface; diffuse thickening of the iris, iris' gray color, and considerable dilatations of the vessels were also noticed. Red reflex was apparent but the evaluation of the retina was not possible due to the opacity in the anterior chamber. The intraocular pressure was normal.

We diagnosed the case as acute iritis of the left eye. We started topical mydriatics and corticosteroids treatment and prescribed oral corticosteroids and antibiotics. The maintaining dose of cytostatics remained at the same level. After a short-lasting improvement of the condition, during which the anterior chamber had become clearer and the visual acuity recovered to $6 / 12$, we discovered the oedema of the macula to the extent of 2 PD in the affected eye. The child's general health condition was satisfactory; repeated results of the sternal and lumbal punctures were negative. Nevertheless, we clarified the diagnosis as an isolated infiltration of the iris. Our decision was based upon the facts that the appearance in the eye (Fig. 7) was completely different from the appearance of common iritis and that the eye did not respond to all therapy applied. The echography examination showed thickening of the uveal tissue (Fig. 8). The iris was still infiltrated, grayish colored in spite of all treatment. The exudate in the anterior chamber was not receding; on the other hand, the posterior synechiae was not appearing. The eye seemed to be completely calm. The visual acuity decreased to finger counting because of opacities in the anterior chamber. Therefore we proposed a systemic treatment with cytostatics and local aktinotherapy. After a consultation with the radiologist, we administered radiation to the eye in 18 doses $0.25 \mathrm{~Gy}$ and $140 \mathrm{~kW}$ three times a week to the total dose of $4.5 \mathrm{~Gy}$. Shortly thereafter, the eye condition turned distinctively better. The exudate in the anterior chamber disappeared, the infiltration of the iris stroma was lower and the leakage to the posterior pole also decreased.

At this time a spherical, painless, reddish infiltrate was noticed under the skin. Excision proved lymphoblostoma with a higher risk of malignance. Therefore, a systemic therapy according to the relapse schedule (ALL-BFM-87 REZ) in a modification with high doses of Methotraxat was started on March 16, 1992. However, the treatment could not be finished. The boy died of the cytostatic therapy complication on May 4, 1992.

Histopathologic study proved leukemic infiltrates of chorioidea, the same changes were detected in corpus ciliare and iris. There was no evidence of leukemia in other structures of the left eye as shown in the Fig. 9. Histopathologic study proved infiltration of the spleen and both testes.

\section{Discussion}

The diagnosis of ocular involvement is usually set after the diagnosis of acute leukemia or during the relapse of the disease.

Ells et al (8) bring to attention the possibility of the fact that the initial symptom of acute leukemia can be found in the eye. They reported a case of an 11-month-old child with unilateral hypopyon and nodules of the iris. The first signs of acute myeloid leukemia appeared 3 weeks after their ocular findings.

Our patient's leukemic infiltration of the iris with pseudohypopyon arose in spite of the fact that there was repeatedly no evidence of relapse of the disease in the bone marrow and central nervous system.

Pracentesis of the anterior chamber and cytologic examination of the aqueous humour is very useful in determining the differential diagnosis $(2,11,12,18,20$, $)$ since it helps a fast diagnosis of extramedullar leukemic infiltration of the iris. It also enables the administration of adequate therapy - especially to patients in remission of the disease.

We were reluctant to use these methods of examination not only because of the preceding administration of corticosteroids and cytostatics but also because of the poorly-healing incision - the result of the catheter application that was necessary for the cytostatics therapy. 


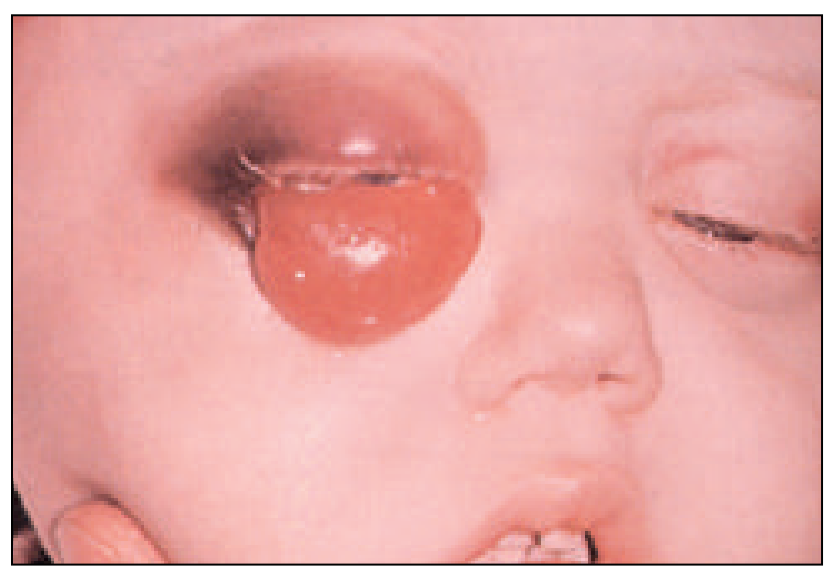

Fig. 1: Orbital infiltration with painful proptosis, lid oedema and chemosis

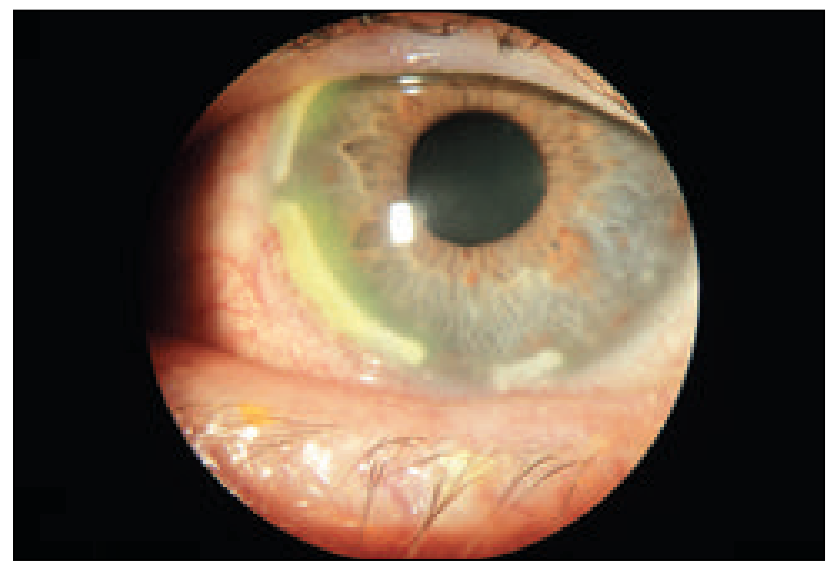

Fig. 3: Infiltrates at the limbus of the cornea

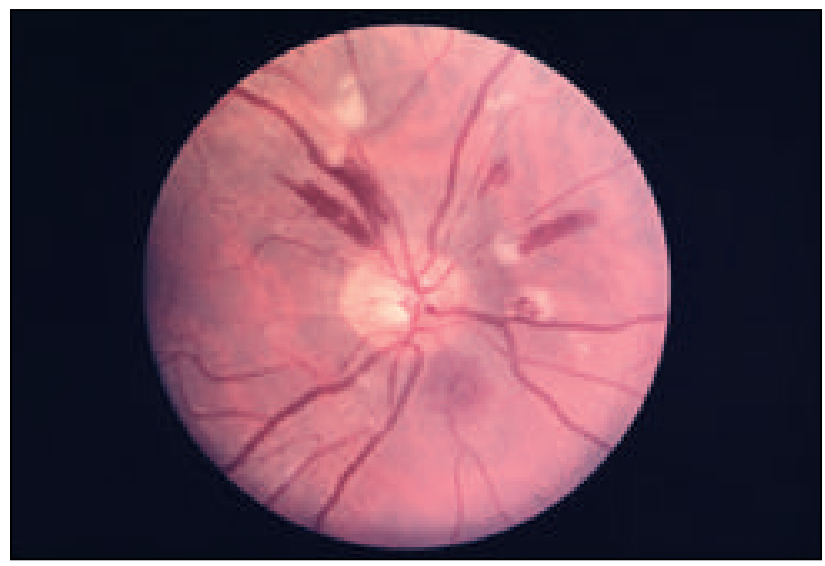

Fig. 5: Flame - shaped hemorrhages with pale centres (Roth's spots)

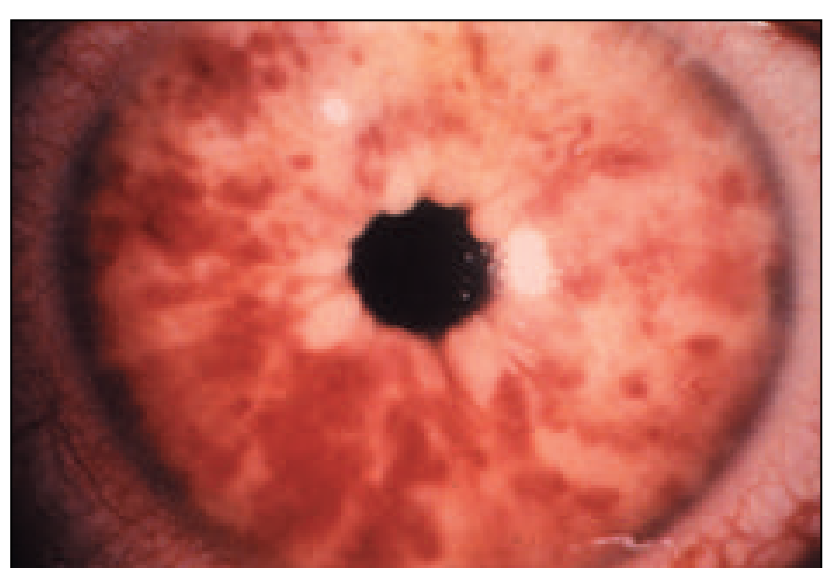

Fig. 2: Diffuse iris infiltrates and scattered stromal hemorrhages

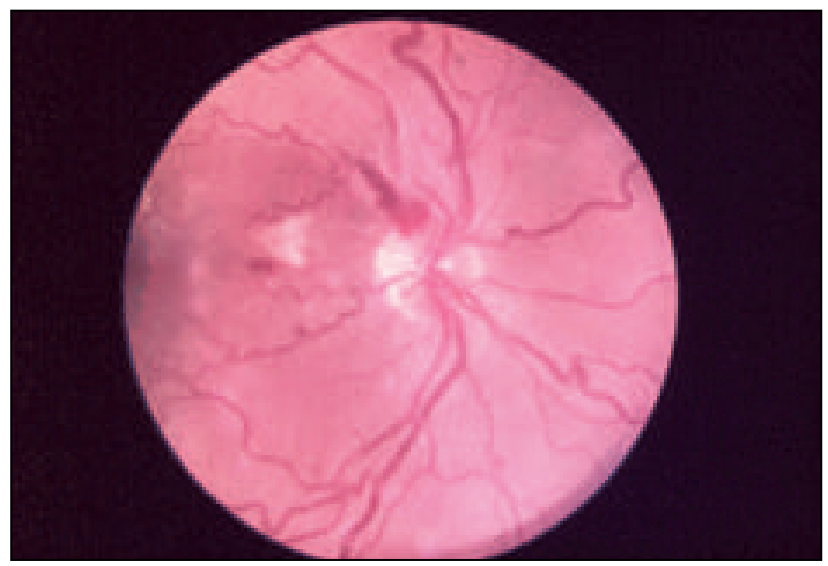

Fig. 4: Venous tortuosity and dilatation with flame - shaped retinal hemorrhages

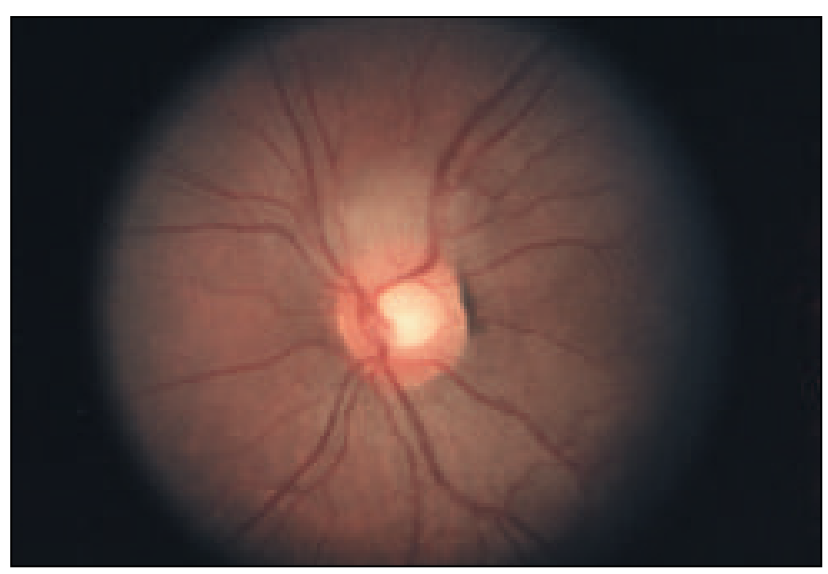

Fig. 6: Leukemic infiltration of the optic nerve 


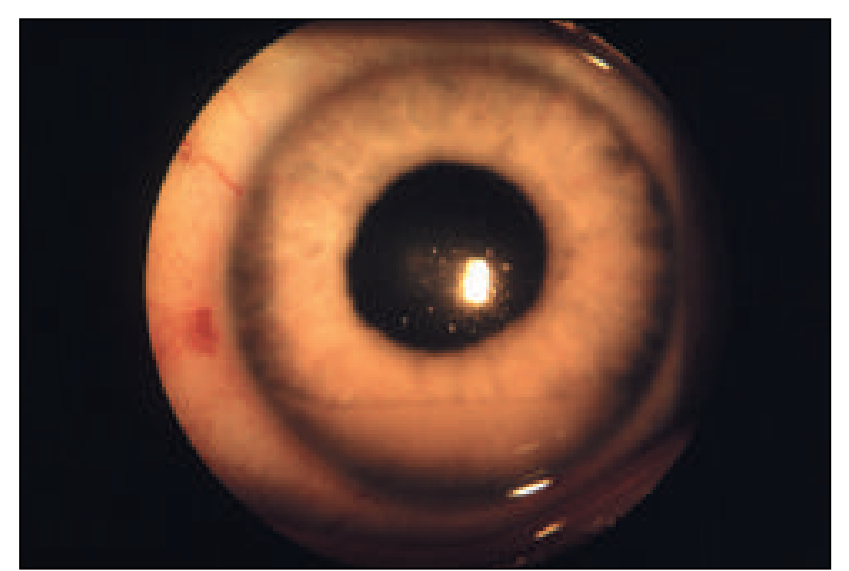

Fig. 7: Leukemic hypopyon in the anterior chamber of the left eye

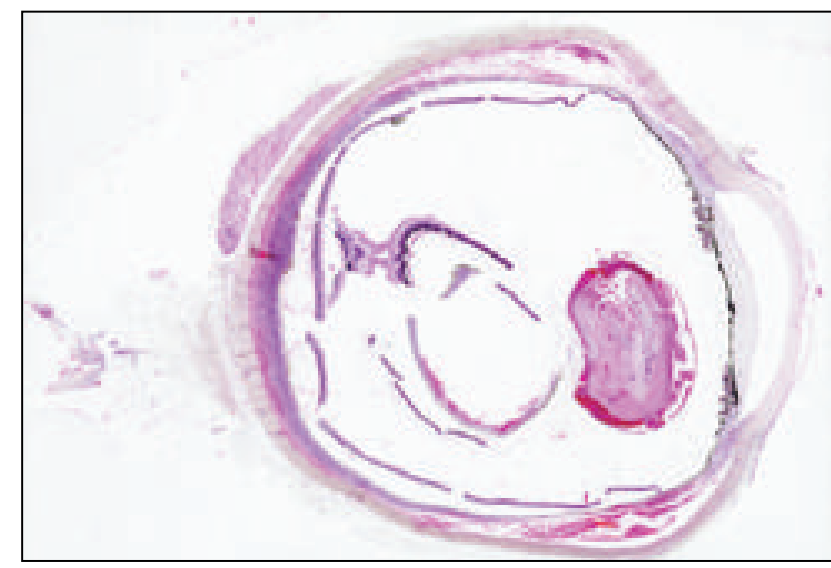

Fig. 9: Section through left globe revealing leukemic infiltration of iris, ciliary body and chorioidea

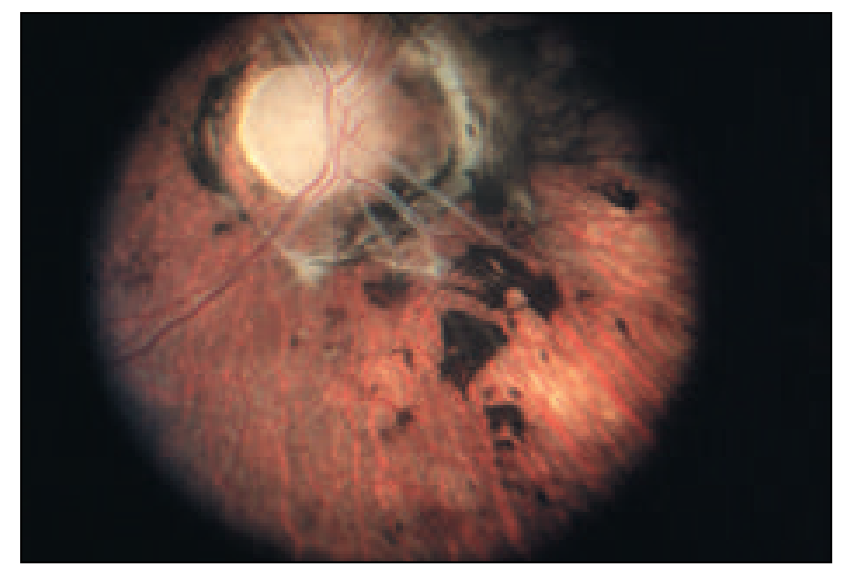

Fig. 11: Atrophy of the optic disc, white retinal vessels and peripapillary pigmentations

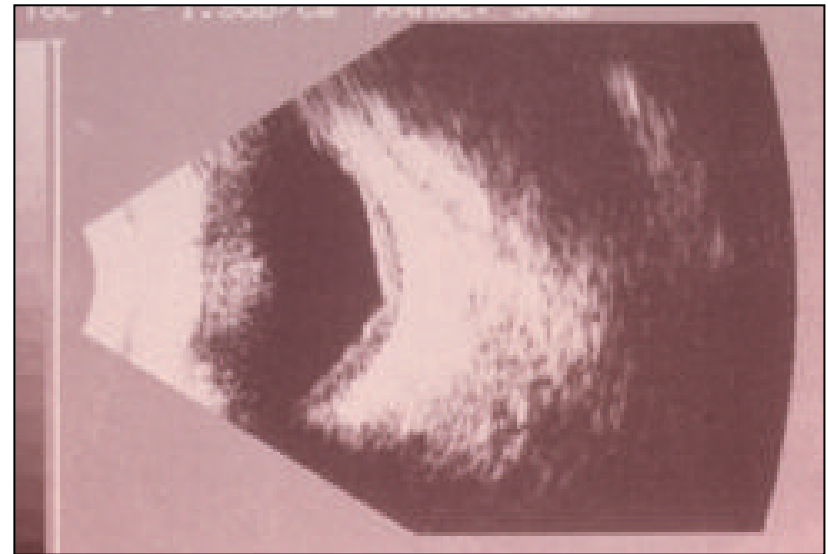

Fig. 8: Ultrasonogram of the left eye shows leukemic infiltration of the chorioidea

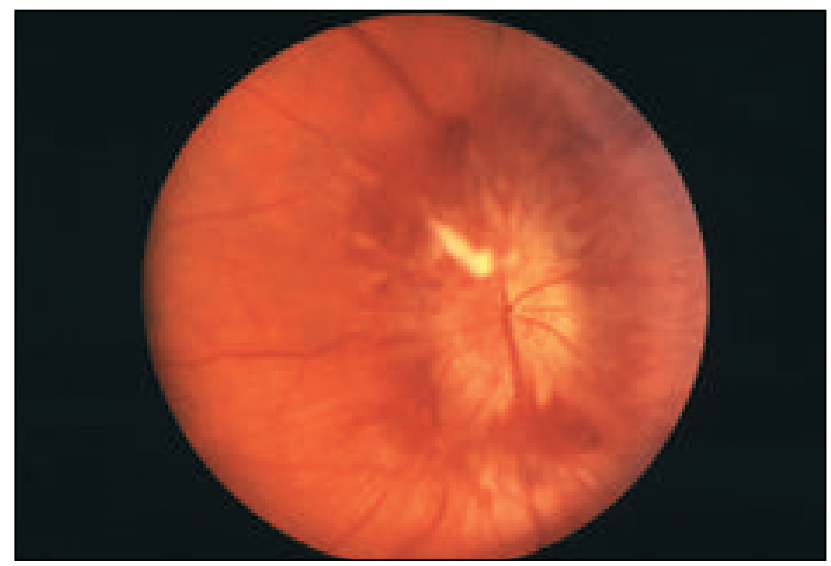

Fig. 10: Leukemic infiltration of the optic nerve with hemorrhages

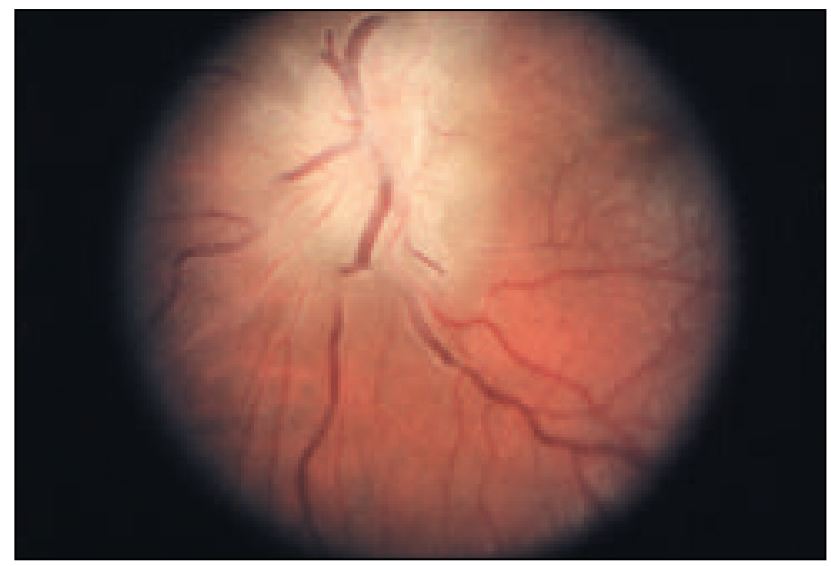

Fig. 12: Oedema of the optic nerve with venous tortuosity and dilatation 
The course the disease took in our case was different from the course that Britt et al (3) described. They noticed the leukemic iris infiltration in a form of heterochromia which was proved by the autopsy 7 months later.

Also in studies of Zakka et al. (20) and Hatvani et al. (12) the diagnosis of isolated leukemic iritis was done when the illness had already been complicated by secondary glaucoma. The leukemic infiltration in chamber's angle caused the bleeding into the anterior chamber.

Isolated leukemic infiltration in form of iritis can be the first sign of the disease as described by Ells et al. (8). Decker et Burnstine (5) described it as the only sign of the disease relapse or it could be preceding the relapse (2). Harrer et al. (11) draws our attention to the typical picture of grayish-white exudate - pseudohypopyon and frequent hemorrhage into the the anterior chamber. The distinction of isolated leukemic infiltration in form of iritis is necessary for an early therapy application.

Hatvani et al. (12) asserts that the doses 1,25 - 4,5 Gy divided into single doses administered during the course of 4 weeks should not have any cataractogenous effects. In spite of this fact, tiny opacities in the anterior and posterior pole of the lens were noted in our case as the result of the same therapy.

The diagnosis of the relapse of the disease was done according to the clinical picture and the echography. The effect of the therapy and the follow-up histopathologic examination, which proved infiltrates of the iris, corpus ciliare and choroidea, showed that the diagnosis of the disease relapse was correct.

\section{Leukemic infiltrates of the optic nerve}

The studies on leukemic infiltrates of the optic nerve are sporadic (4, 13, 19). Echography (4) and magnetic resonance tests (19) are the most important examinations for fixing the differential diagnosis and, according to Yamamoto et al. (19) the differential diagnosis should be determined as soon as possible in order to begin an adequate therapy.

We present a case of a 4-1/2-year-old girl with the diagnosis of acute lymhoblastic leukemia that was fixed in November, 1980. The child was treated in compliance with Maurer's method. The basic therapy was discontinued three years later due to the patient's good clinical state.

In October, 1987, fever occurred and the patient's ability to walk quickly diminished to spastic paraparesis of the legs with preservation of the sensivity. The examination proved lymphoblastic lymphoma in the region of Th $5-6$.

The laminectomy of Th 4 - 7 with aktinotherapy and cytostatic therapy according to schedule ALL-BMF-83 with high doses of Methotraxat was done. After the rehabilitation, the legs movement was totally restored and the child didn't experienced any difficulties till November, 1991.

At that time, the girl was examined at the eye clinic in Košice for the decrease of the visual acuity to $5 / 15$ and for pains behind the right eye. The diagnosis was neuritis of the right eye. The patient was examined on November 25, 1991 at the eye clinic in Hradec Králové.

Ocular finding:

VA OR: 6/60. The eye was completely calm, all spaces were transparent, the disc of the optic nerve was oedematic with the prominence to $+5,0 \mathrm{D}$, with deposits of exudates (Fig. 10), and with numerous hemorrhages on the disc. The exudates were also found around the disc and in the middle periphery.

VA OL: 6/6. The left eye was calm, all spaces were transparent, the disc was restricted and on the same level. There were tiny hemorrhages and deposits of exudates around the disc and in the middle periphery. Our prognosis indicated the relapse of the diseases. The examination of cerebrospinal fluid proved the prognosis' correctness. Thereafter, the treatments according to the relapse schedule (BFM-REZ-83 at first; BFM-REZ-87 later) were commenced. The cerebrospinal fluid findings turned to a normal state again.

However, the visual acuity of the right eye decreased to incerta. The disc was restricted, on the same level, atrophic, pale. In the distance of $1 / 2$ PD nasally, there was a light ring with well-noticeable pigmentations which continued nasally as deposits of bone-like cells, retinal vessels were sheated to the middle part of retina (Fig. 11). On the left side, there was visual acuity of $6 / 6$, outer and intraocular findings were normal.

Until December, 1993 (i.e. 13 years after the diagnosis), the child experienced no difficulties except for the common signs of recession of bone marrow. However, at the end of December 1993, the girl was repeatedly examined for temporary failure of visual acuity of the left eye at the eye clinic in Košice. Allegedly, the failure always settled. The diagnosis was fixed as neuritis of the left side. VA was $5 / 15$, the girl was treated with Prednison and Azamun.

The patient came to the eye clinic in Hradec Králové in May, 1994.

VA OR light projection: incerta.

VA OL light projection: certa. Both eyes showed afferent pupillary defect.

OR: The eye was in a devergency of 10 degrees. Retina showed the same findings as shown in Fig. 11.

OL: The eye was calm, the disc was swollen to $+2,0$ $\mathrm{D}$ with dilated vessels, no hemorrhages were detected (Fig. 12). The echography of the left orbit proved the prominence of the disc and diffuse thickening of the left optic nerve.

The state was closed as both-sided atrophy of the discs due to the infiltrates in the region of the optic nerves during the course of the basic disease. Computed tomography of the brain did not prove the signs of intracranial expansive process.

The patient died within a short period of time at the department of hemato-oncology in Košice with both-sided amarousis due to the irreversible course of the disease.

\section{Discussion}

According to Ellis et al (7), the studies on infiltration of the optic nerve are rare. The infiltrations are almost always 
the signs of the extramedullar manifestations. We encounter them only in acute leukemia states. They could present the isolated extramedullar relapse of the disease (4).

Nikaido et al. (14) informed about five patients who were treated with combined therapy including chemotherapy, intrathecal injections of cytostatics together with radiotherapy. The results of visual functions of such therapy were always disappointing.

Better results were described by Yamamoto et al. (19). They were the first team to observe their patient's recovery of visual functions in leukemic infiltration of the right optic nerve after administrating 40 Gy of radiation to the brain and right orbit. The visual acuity improved from movement vision in front of the eye to 20/20 within 3 weeks.

Also Camera et al. (4) observed the recovery of visual functions in one of his two patients who were treated immediately for the isolated relapse of the optic nerve. He recommended the use of the most sensitive method - A scan echography for an early diagnosis of the eye involvement in acute leukemia cases.

Kaikov (13) described visual acuity improvement in infiltration of the optic nerve after the immediate irradiation of the orbit as well as the whole CNS. Also, according to him, an early children diagnosis determination is very difficult most of the time. Children ophthalmologists should keep in mind the infiltration of the optic nerve so that the diagnosis can be fixed immediately and the proper treatment can be launched at once. In such event, the visual acuity can be saved.

\section{Conclusions}

The probability of extramedullar complications occurrences is higher when prolonging the lives of patients who suffer from acute leukemia. We can find such occurrences especially in organs with high barrier such are the CNS or the eye. In these organs, there is lower concentration of drugs and, therefore, the number of complications is quite high and their frequent occurrence is not surprising. It is necessary to know of such complications so that the patient can receive an immediate and adequate treatment. The close cooperation of ophthalmologist, radiologist and physician can lead to an early diagnosis, adequate therapy and, consequently, to the visual functions improvement in such suffering patients.

\section{References}

1. Allen RA, Straatsma BR. Ocular involvement in leukaemia and allied disorders. Arch of Ophthal 1961;66:490-508. 2. Ayliffe W, Foster CS, Marcoux P. et al. Relapsing acute myeloid leukemia manifesting as hypopyon uveitis. Am J Ophthalmol 1995;119:361-4.

3. Britt JM, Karr DJ, Kalina RE. Leukemic iris infiltration in recurrent acute lymphocytic leukemia. Arch Ophthal 1991; 109:1456.

4. Camera A, Piccririllo G, Cennamo G et al. Optic nerve involvement in acute lymphoblastic leukemia. Leuk Lymphoma 1993;11(1-2):153-5.

5. Decker EB, Burnstine RA. Leukemic relapse presenting as acute unilateral hypopyon in acute lymphotic leukemia. Ann Ophthalmol 1993;25(9):346-9.

6. Duke-Elder Sir St. System of Ophthalmology. Vol IX. Kimpton London 1966;634.

7. Ellis W, Little HL. Leukemic infiltration of the optic nerve head. Amer J Ophthalmol 1973;75:867-71.

8. Ells A, Clarke WN, Noel LP. Pseudohypopyon in acute myelogeneous leukemia. J Pediastr Ophthalmol Strabismus 1995;32(2):123-4.

9. Fischman ML, Bean SCh, Cogan DG. Optic atrophy following prophylactic chemotherapy and cranial radiation for acute lymphocytic leukemia. Amer J Ophthalmol 1976;82:571-6.

10. Friedman B. Hematologie v praxi. Státní nakladatelství Galen:1994.

11. Harrer S, Krieger O, Rigal K, Rubey F, Weber R, Lutz D. Seltene Form der Augenbeteiligung bei akuter lymphatischer Leukämie. Klin Mbl Augenheilk 1984;185:451-3.

12. Hatvani I, Balázs E. Isolierte Leukämische Iritis im Kinderalter. Klin Mbl Augenheilk 1988;192:703-5.

13. Kaikov Y. Optic nerve head infiltration in acute leukemia in children: an indication for emergency optic nerve radiation therapy. Med Pediatr Oncol 1996;26(2): 101-4.

14. Nikaido H, Mishima H, Ono H, Choshi K, Dohy H. Leukemic involvement of the optic nerve. Amer J Ophthalmol 1988;105: 294-8.

15. Ohkoshi K, Tsiaras WG. Prognostic importance of ophthalmic manifestations in childhood leukaemia. $\mathrm{Br}$ J Ophthal 1992;76(11):651-5.

16. Pierro L, Brancato R, Zaganelli E, Guarisco L, Lanzetta P. Ocular involvement in acute lymphoblastic leukemia: an echographic study. Int Ophthalmol 1992;16(3):159-62.

17. Soylu M, Tanyeli A, Ozdemir N, Eroglu A,Ersoz TR. Ocular involvement in childhood leukemias. Turk J Pediatr 1994; 36(1):35-41.

18. Schwartz M, Schumann GB. Acute leukemic infiltration of the vitreous diagnosed by pars plana aspiration. Am Ophthalmol 1980;90:326-30.

19. Yamamoto N, Kiyosawa M, Kawasaki T, Miki T, Fujino T, Tokoro T. Successfully treated optic nerve infiltration with adult T-cell lymphoma. J Neuroophthalmol 1994;14(2):81-3.

20. Zakka KA, Yee RD, Shorr N, Smith GS, Petit TH, Foos RY. Leukemic iris infiltration. Amer J Ophthalmol 1980;89:204-9.

Submitted May 1997.

Accepted June 1997.

Doc. MUDr. Dagmar Hejcmanová, CSc., Department of Ophthalmology, 50005 Hradec Králové, Czech Republic. 